\title{
RAPID AND RELIABLE HEALING OF CRITICAL SIZE BONE DEFECTS WITH GENETICALLY MODIFIED SHEEP MUSCLE
}

\author{
F. Liu ${ }^{1,2, \delta}$, E. Ferreira ${ }^{1,2}$, R.M. Porter ${ }^{1,2}$, V. Glatt ${ }^{1,2, \uparrow}$, M. Schinhan ${ }^{1,3}$, Z. Shen ${ }^{1,2}$, M.A. Randolph ${ }^{4}$, C.A. Kirker-Head ${ }^{5}$, \\ C. Wehling ${ }^{1,6}$, M.S. Vrahas ${ }^{2,4}$, C.H. Evans ${ }^{1,2, \S, *}$ and J.W. Wells ${ }^{1,2, *}$
${ }^{1}$ Center for Advanced Orthopaedic Studies, Beth Israel Deaconess Medical Center, Harvard Medical School, Boston, MA, USA
${ }^{2}$ Collaborative Research Centre: AO Foundation, Davos, Switzerland
${ }^{3}$ Department of Orthopaedic Surgery, University of Vienna Medical School, Vienna, Austria \\ ${ }^{4}$ Department of Orthopaedic Surgery, Massachusetts General Hospital, Harvard Medical School, Boston, MA, USA \\ ${ }^{5}$ Department of Clinical Sciences, Cummings School of Veterinary Medicine, Tufts University, \\ North Grafton, MA, USA \\ ${ }^{6}$ Ludwig Maximilan University Medical School, Munich, Germany \\ Present affiliations: \\ ${ }^{\delta}$ Institute of Plastic and Reconstructive Surgery, WeiFang Medical University, Shandong, China \\ ${ }^{\dagger}$ Queensland University of Technology, Brisbane, Australia \\ $\$$ The University of Queensland Diamantina Institute, The University of Queensland, Brisbane, Australia
}

\begin{abstract}
Large segmental defects in bone fail to heal and remain a clinical problem. Muscle is highly osteogenic, and preliminary data suggest that autologous muscle tissue expressing bone morphogenetic protein-2 (BMP-2) efficiently heals critical size defects in rats. Translation into possible human clinical trials requires, inter alia, demonstration of efficacy in a large animal, such as the sheep. Scale-up is fraught with numerous biological, anatomical, mechanical and structural variables, which cannot be addressed systematically because of cost and other practical issues. For this reason, we developed a translational model enabling us to isolate the biological question of whether sheep muscle, transduced with adenovirus expressing BMP-2, could heal critical size defects in vivo. Initial experiments in athymic rats noted strong healing in only about one-third of animals because of unexpected immune responses to sheep antigens. For this reason, subsequent experiments were performed with Fischer rats under transient immunosuppression. Such experiments confirmed remarkably rapid and reliable healing of the defects in all rats, with bridging by 2 weeks and remodelling as early as 3-4 weeks, despite BMP-2 production only in nanogram quantities and persisting for only 1-3 weeks. By 8 weeks the healed defects contained well-organised new bone with advanced neo-cortication and abundant marrow. Bone mineral content and mechanical strength were close to normal values. These data demonstrate the utility of this model when adapting this technology for bone healing in sheep, as a prelude to human clinical trials.
\end{abstract}

Key Words: Bone healing, gene therapy, muscle, adenovirus, bone morphogenetic protein, sheep, rat, immunosuppression.
*Address for correspondence:

Dr Chris Evans

Rehabilitation Medicine Research Center

Mayo Clinic, 200 First Street SW

Rochester, MN 55905, USA

Telephone Number: 1-507-255-0099

E-mail: evans.christopher@mayo.edu

\section{Introduction}

Although gene therapy is usually associated with the treatment of rare Mendelian diseases, it holds much potential for solving more common clinical problems, such as those presented by injuries to the musculoskeletal system (Evans and Robbins, 1999; Evans et al., 2004). Bone healing is a case in point (Pensak and Lieberman, 2013; Baltzer et al., 2000; Niyibizi et al., 1998). Even though the long bones constitute one of the few organs in the body that can regenerate spontaneously without scarring, large segmental defects beyond a certain critical size fail to heal (Muschler et al., 2010).

Depending upon the setting, distraction osteogenesis and osseous autografting are the treatments of choice for the clinical management of large segmental defects (reviewed by DeCoster et al., 2004). While often successful, the former technique is inconvenient, slow and often painful. Autografting, on the other hand, is constrained by the limited amount of autologous bone available for grafting and donor site morbidity. Bone harvested from cadavers provides an alternative source of graft material and is available in almost unlimited quantities. However, the processing of allograft bone kills its cells, so that the implanted material is dead bone that fails to integrate with the adjacent living bone or remodel. Structural allografts thus accumulate microfractures and ultimately fail (DeCoster et al., 2004).

Much research focuses on improving the treatment of large segmental defects through regenerative approaches using various combinations of novel scaffolds, osteogenic growth factors, progenitor cells and mechanical stimulation 
(Evans, 2013; Dumic-Cule et al., 2015). Our group has adopted the strategy of developing simple, intra-operative technologies that do not require scaffolds or the ex vivo expansion of autologous cells (Evans et al., 2007).

From this perspective, the highly osteogenic properties of skeletal muscle are conspicuous and best exemplified by the disease fibrodysplasia ossificans progressiva (FOP). An activating mutation in Alk2, that encodes a bone morphogenetic protein (BMP) receptor, leads to progressive heterotopic ossification through an endochondral process (Shore et al., 2006). This confirms that a sustained BMP signal promotes osteogenesis in human skeletal muscle, which is important given the oftenpoor correlation between results obtained in rodent models and clinical data from human subjects (Seok et al., 2013). The occurrence of heterotopic ossification in muscle after blast injuries, burns, traumatic brain injury, spinal cord injury and certain types of joint surgery further illustrates its osteogenic potential (Nauth et al., 2012 ).

Gene transfer offers one way to provide a sustained BMP signal in vivo. Of the various gene transfer vectors, adenovirus offers many advantages because it is straightforward to produce at high titer, is highly infectious and has been widely used in human clinical trials (Crystal, 2014). Moreover, the natural history of the recombinant virus ensures its biological clearance, and hence loss of transgene expression, within about 6 weeks (Baltzer et al., 1999). This time-line seems well matched to the needs of bone healing.

From such considerations we designed a strategy to heal bone based upon the genetic modification of muscle using recombinant adenovirus vectors carrying human BMP-2 cDNA (Ad.BMP-2). Ultimately, this could be implemented intra-operatively, with muscle biopsies harvested, genetically modified and implanted into a defect in one session. The physical properties of muscle are such that no scaffold is needed. This strategy was tested previously in rats, with encouraging preliminary data that also demonstrated the promise of autologous fat in this regard (Evans et al., 2009).

Translating research findings into clinical protocols requires demonstration of efficacy in large animal models, and this step has become a bottleneck for the field of bone healing (Evans, 2010; Evans, 2011a,b). Sheep are a favoured species in translational studies of this kind, because of their size, weight and bone structure (Muschler et al., 2010). Previous attempts to heal osseous lesions in sheep by gene therapy have met with mixed success (Egermann et al., 2006a,b). Reports that sheep and human osteoprogenitors are less responsive to BMP-2 than equivalent rodent cells (Diefenderfer et al., 2003) may be of relevance.

Because sheep and other large animals are expensive to buy and cumbersome to house, operate and process, it is not possible to perform multiple, large, well-powered studies to examine each variable in the same way as is usual with rodents. For this reason, we developed a translational model whereby genetically modified sheep muscle or fat were implanted into diaphyseal, femoral defects in immunosuppressed rats. This enabled us to isolate and study the crucial biological question of whether genetically modified sheep tissues could heal a critical size defect in vivo, while keeping all other variables constant. The results were dramatic.

\section{Materials and Methods}

\section{Preparation of adenovirus vectors}

First generation adenovirus $(\triangle \mathrm{E} 1, \Delta \mathrm{E} 3)$, serotype 5, carrying human BMP-2 cDNA (Ad.BMP-2) or green fluorescent protein (GFP) cDNA (Ad.GFP) under the transcriptional control of the human cytomegalovirus early promoter were constructed by cre-lox recombination as previously described (Gouze et al., 2004; Mi et al., 2003). Viruses were propagated in 293 cells (ATCC, Manassas, VA, USA), purified on caesium-chloride gradients, and dialysed against $10 \mathrm{mM}$ Tris- $\mathrm{HCl}$ (pH 7.8), $150 \mathrm{mM} \mathrm{NaCl}$, $10 \mathrm{mM} \mathrm{MgCl}_{2}$, and $4 \%$ sucrose buffer. Viral titers were estimated as $10^{12}$ to $10^{13}$ viral particles (vp)/mL by optical density and $10^{10}$ to $10^{11}$ plaque forming units $(\mathrm{pfu}) / \mathrm{mL}$ by standard plaque assay.

\section{Genetic modification of muscle and fat implants}

Sheep muscle and fat were freshly harvested from healthy sheep being euthanised for other purposes at the BIDMC Slosberg Landay Animal Facility, the Department of Orthopaedic Surgery at Massachusetts General Hospital (Boston, MA, USA), and The Cummings School of Veterinary Medicine (North Grafton, MA, USA).

Soleus muscle and sub-cutaneous fat were harvested aseptically from American Polypay female sheep, approximately 18 months of age, and carefully prepared to form slices approximately $2 \mathrm{~mm}$ thick; $4 \mathrm{~mm} \times 2 \mathrm{~mm}$ discs were produced with a $4 \mathrm{~mm}$ skin biopsy punch. Groups of 4 discs were placed into wells of 48 -well plates and a $50 \mu \mathrm{L}$ aliquot of adenovirus suspension $\left(10^{10} \mathrm{vp} /\right.$ well $)$ was added to each well. The plates were incubated $\left(37^{\circ} \mathrm{C} ; 5 \%\right.$ $\mathrm{CO}_{2}$ ) for $2 \mathrm{~h}$. The discs were then washed with phosphate buffered saline (PBS), and subsequently $1 \mathrm{~mL}$ of medium (Dulbecco's Modified Essential Medium, $10 \%$ foetal calf serum, $50 \mu \mathrm{g} / \mathrm{mL}$ ascorbic acid, $10 \mathrm{mM} \beta$-glycerol phosphate) was added to each well. Conditioned medium was collected at $72 \mathrm{~h}$ and BMP-2 content measured using a commercial ELISA kit (R\&D Systems, Minneapolis, MN, USA).

\section{Rats}

Male Fischer F344 rats were purchased from Charles River Laboratory (Wilmington, MA, USA). Athymic rats were purchased from Charles River Laboratory and Taconic Farms (Germantown, NY, USA). All animals were 12 weeks of age at the time of surgery. Rats were housed in a central animal care facility with 12-h light cycles and were given chow and water ad libitum. Animal care and experimental protocols were followed in accordance with National Institutes of Health guidelines and approved by the Beth Israel Deaconess Medical Center Institutional Animal Care and Use Committee. The numbers and types of rats assigned to the various experiments are shown in Table 1. 
Table 1. Groups of animals used in the experiments described in this paper.

\begin{tabular}{|c|c|c|c|c|}
\hline \multirow{4}{*}{ Strain of Rat } & Implants & $\begin{array}{c}\text { Immunosuppression } \\
\text { FK506+ SEW2871 }\end{array}$ & Adenovirus & $\begin{array}{c}\text { Number of } \\
\text { Rats }\end{array}$ \\
\hline \multirow{3}{*}{ Athymic } & Sheep Fat & & Ad.BMP-2 & 6 \\
\cline { 2 - 5 } & Sheep Muscle & - & Ad.BMP-2 & 12 \\
\hline \multirow{5}{*}{ Fischer 344 } & Sheep Fat & + & Ad.BMP-2 & 3 \\
\cline { 2 - 5 } & Sheep Muscle & + & Ad.BMP-2 & 55 \\
\cline { 2 - 5 } & Sheep Muscle & - & Ad.BMP-2 & 17 \\
\cline { 2 - 5 } & Sheep Muscle & + & Ad.GFP & 6 \\
\cline { 2 - 5 } & rhBMP-2 $11 \mu \mathrm{g}+$ Collagen sponge & - & N/A & 6 \\
\cline { 2 - 5 } & rhBMP-2 $11 \mu \mathrm{g}+$ Collagen sponge & + & N & 6 \\
\hline
\end{tabular}

\section{Surgical procedure}

Animals were divided randomly into the experimental groups described below. A $5 \mathrm{~mm}$, critical-sized, midfemoral defect was created in the right hind limb of each rat and used in all the experiments. Briefly, Fischer rats were anaesthetised by administration of isoflurane $(2 \%$ at $2 \mathrm{~L} / \mathrm{min}$ ) and given antibiotic (cefazolin, $20 \mathrm{mg} / \mathrm{kg}$ ) and analgesic (meloxicam, $1.0 \mathrm{mg} / \mathrm{kg}$ ) subcutaneously before surgery.

Under sterile conditions, a $4 \mathrm{~cm}$ incision was made on the posterolateral thigh. The lateral intermuscular septum with respect to the femur was dissected to expose the diaphysis of the femur. The periosteum was removed on the anterolateral femur. Using a demo fixator as a guide, four predrilled pin holes were made in the central portion of the femoral shaft with a sterile $0.79 \mathrm{~mm}$ drill bit. The external fixator (RISystem AG, Davos, Switzerland) was then secured in position by screwing 4 precise pins into both cortices of the rat femora through these predrilled holes and the external fixator. A saw guide was used to position and create the $5 \mathrm{~mm}$ segmental defect using a $0.22 \mathrm{~mm}$ wire Gigli saw. After the defect was created, the saw guide was removed and 4 discs of sheep muscle or fat were press-fit into the defect area created in the rat femur. The wound was repositioned in layers with 3-0 Vicryl sutures and the incision site closed using Autoclip wound clips.

\section{Immunosuppression}

FK506 was dissolved in ethanol:Tween 80:saline 1:0.2:8.8 (v/v) to a concentration of $6.67 \mathrm{mg} / \mathrm{mL}$ FK506. SEW2871 was dissolved in ethanol:Tween 80 :saline - 2.7:0.2:7.1 (v/v) to a concentration of $3.33 \mathrm{mg} / \mathrm{mL}$ SEW2871. These two solutions were mixed in a $1: 1$ ratio to provide a solution containing $3.33 \mathrm{mg} / \mathrm{mL}$ FK506 and $1.66 \mathrm{mg} / \mathrm{mL}$ SEW2871. Each rat received a daily $100 \mu \mathrm{L}$ subcutaneous injection of this mixture during the period of immunosuppression.

\section{Immunoassays}

Cell-mediated immune response to sheep cells

Sheep fat cells were irradiated at 30 Gy and plated out in triplicate in 96-well U bottomed plates (Greiner Bio-One, Stonehouse, UK), serially diluted 1:2 from $1 \times 10^{4}$ cells/ well down to $1.25 \times 10^{3}$ cells/well. Splenocytes were harvested from the spleens of naïve and transplanted rats and depleted of red-blood cells using Red Blood Cell Lysing Buffer $(0.155 \mathrm{M}$ ammonium chloride in 0.01 $\mathrm{M}$ Tris- $\mathrm{HCl}$ buffer, Sigma, St Louis, MO, USA), and B-cells using CD45RA microbeads (Miltenyi Biotech, Cambridge, MA, USA) according to the manufacturer's instructions. The splenocytes were then added to the plate at $10^{5}$ cells/well (final volume: $200 \mu \mathrm{L} /$ well). After $5 \mathrm{~d}$ at $37{ }^{\circ} \mathrm{C}$, splenocyte proliferation was assessed by bromodeoxyuridine (BrdU) incorporation over $6 \mathrm{~h}$ using a colorimetric immunoassay kit (Roche Applied Science, Pleasanton, CA, USA) according to the manufacturer's instructions.

\section{Humoral response to sheep cells}

Serum samples from naive and transplanted rats were collected and analysed for the presence of anti-sheep IgG and IgM by FACS using sheep fat cells as targets. Sheep cells were removed from culture and resuspended at $2 \times 10^{6}$ cells $/ \mathrm{mL}$ in PBS; $1 \times 10^{5}$ cells were incubated in triplicate for $30 \mathrm{~min}$ at $4{ }^{\circ} \mathrm{C}$ with serum samples (harvested at the indicated time-points and previously heat inactivated at $56{ }^{\circ} \mathrm{C}$ for $30 \mathrm{~min}$ ) at a final dilution of 1 in 10 . Cells were washed twice, and then incubated with either a 1 in 100 dilution of goat anti-rat IgG FITC or a 1 in 100 dilution of goat anti-rat IgM FITC (both from AbD Serotec, Raleigh, NC, USA) for a further $30 \mathrm{~min}$ at $4{ }^{\circ} \mathrm{C}$. The cells were then fixed with $4 \%$ paraformaldehyde in PBS, washed twice, and analysed by flow cytometry. Data are expressed as a fluorescence index created by dividing the mean fluorescence intensity (MFI) of each experimental serum sample by the MFI of pooled serum derived from multiple naïve rats.

\section{Measurement of BMP-2 in extracts of the defect area}

To assess the temporal expression of BMP-2 in the femoral defect after implantation of Ad.BMP-2 transduced tissue grafts, the tissue in the defect area was collected at 3, 7, 21, 35 and $56 \mathrm{~d}$ and pulverised in stainless steel grinding jars using a TissueLyser II (Qiagen, Hilden, Germany). The resulting tissue powder was extracted with T-PER tissue protein extraction solution (Thermo Fisher Scientific, Rockford, IL, USA) containing protease inhibitors to release protein. The supernatant was collected and diluted 10-fold before BMP-2 measurement using a commercial ELISA kit (R\&D Systems). 


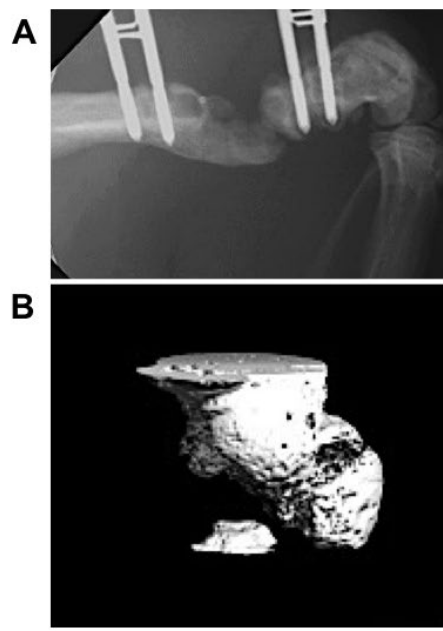

Rat \#1

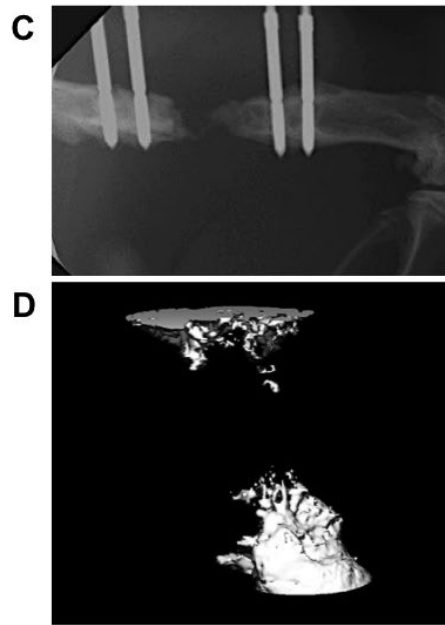

Rat \#3

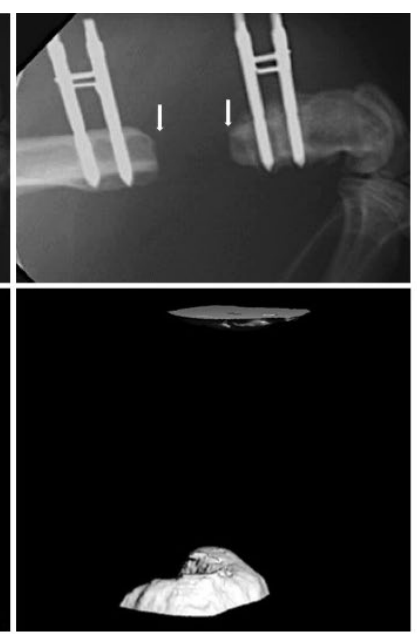

Rat \#2

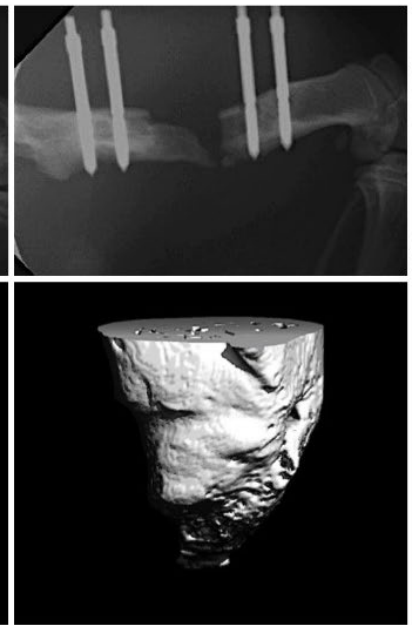

Rat \#4
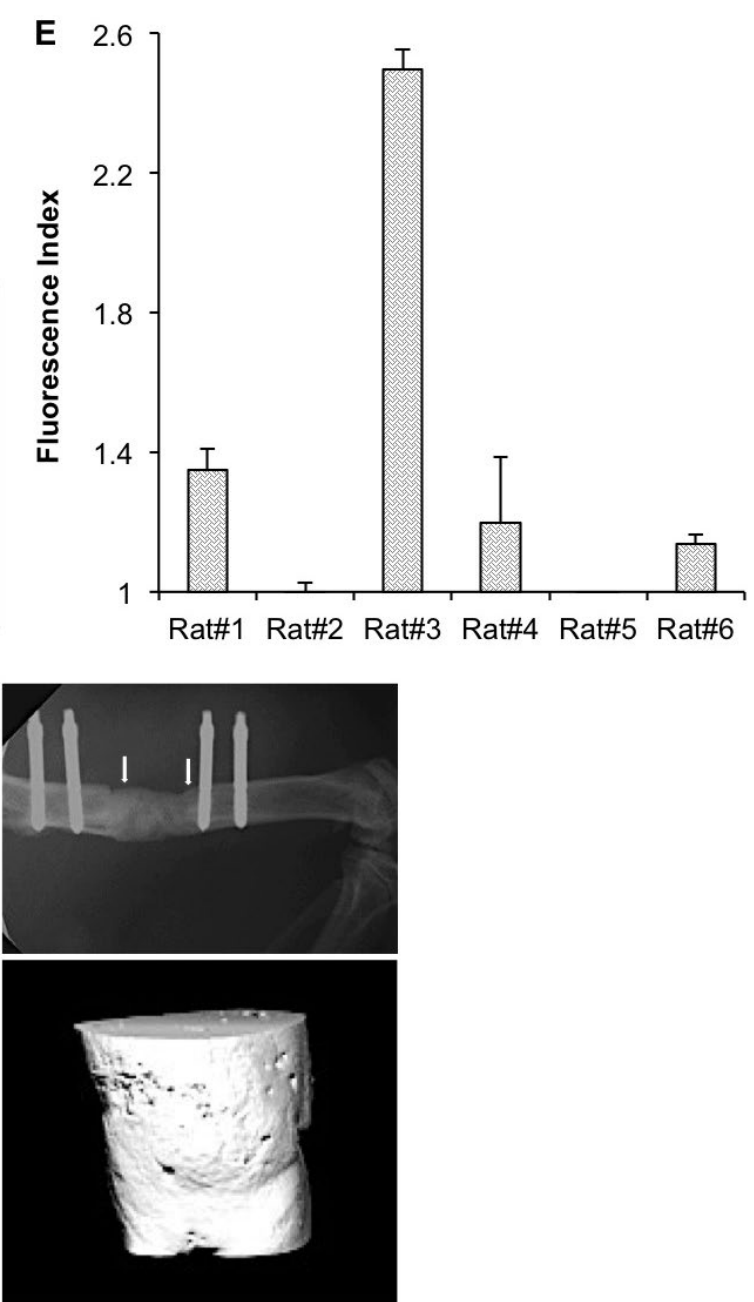

Rat \#5

Fig. 1. Bone healing in athymic rats. Radiologic findings: Representative images of X-ray (A, C) and corresponding high resolution $\mu \mathrm{CT}(\mathbf{B}, \mathbf{D})$ taken at 8 weeks, showing the typical range of bone healing efficacy in athymic rats receiving grafts of genetically modified sheep fat $(\mathbf{A}, \mathbf{B})$ or muscle $(\mathbf{C}, \mathbf{D})$. Arrows in the X-ray images of rats \# 2 and 5 show the edges of the defect. Immunologic findings: Rat anti-sheep IgG xenoantibody responses in six different rats at 8 weeks following sheep muscle implantation $(\mathbf{E})$. Samples were run in triplicate.

\section{Radiographic evaluation}

Serial, weekly radiography using a digital dental X-ray unit was performed on rats under general anaesthesia. Rats were ventrally positioned and the X-ray sensor was placed under the defect area of each femur.

\section{Micro-computed tomography $(\mu \mathrm{CT})$}

The architecture of newly formed bone in the rat segmental defects was examined with a desktop micro-tomographic imaging system ( $\mu$ CT40, Scanco Medical AG, Bassersdorf, Switzerland) equipped with a $10 \mathrm{~mm}$ focal spot microfocus X-ray tube. Femoral defects were scanned using a $20 \mu \mathrm{m}$ isotropic voxel size, at $55 \mathrm{keV}$ energy, $200 \mathrm{~ms}$ integration time, with approximately $500 \mu \mathrm{CT}$ slices per specimen. Evaluation of only a $4 \mathrm{~mm}$ ( 220 slices) central region of the defects was used to exclude any pre-existing intact cortical bone. Total cross-sectional area or the callus size of the defect $\left(\mathrm{TA}, \mathrm{mm}^{2}\right)$, bone area $\left(\mathrm{BA}, \mathrm{mm}^{2}\right)$, and cortical thickness were calculated from $\mu \mathrm{CT}$ images. Images were thresholded using an adaptive-iterative algorithm and morphometric variables were computed from the binarised images using direct, 3D techniques that do not rely on any prior assumptions about the underlying structure.

\section{Dual-energy X-ray absorptiometry (DXA)}

DXA measurements (Bone mineral content, BMC (grammes)) of the defect area were obtained with PIXImus2 apparatus (GE-Lunar, Madison, WI, USA). Briefly, each femoral defect was placed on a lucite block during scanning to simulate soft tissue. The scans were acquired using small animal high-resolution mode. All specimens were evaluated at 8 weeks in the area corresponding to the region of the critical-sized bony defect.

\section{Ex vivo torsion testing}

Specimens were tested to failure in torsion to evaluate mechanical properties of the healed defect in shear. Before the test, both ends of each specimen were embedded in polymethylmethacrylate to provide a reproducible gripping interface with the testing fixture. All femora were tested to failure under regular deformation control and at the constant deformation rate of $5 \mathrm{rad} / \mathrm{min}$. Angular 


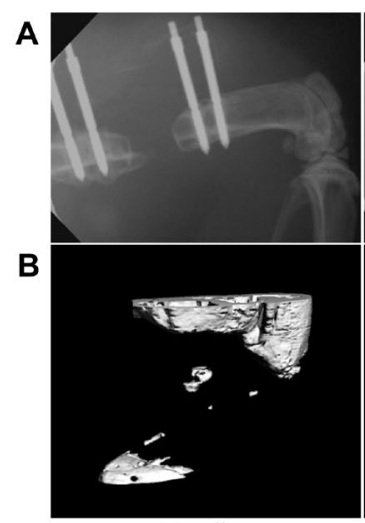

Rat \#a

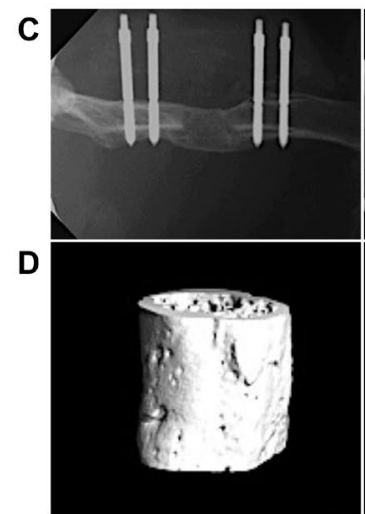

Rat \#d

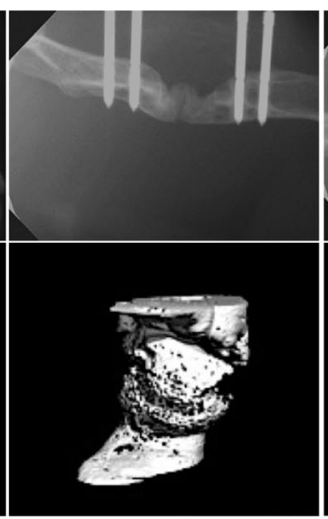

Rat \#b
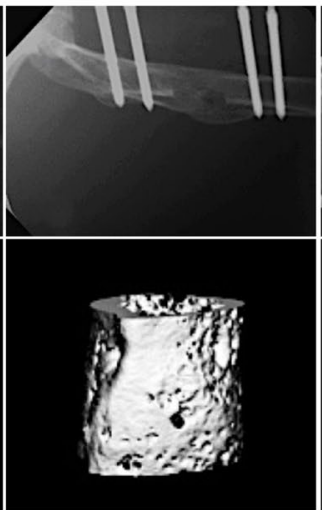

Rat \#e

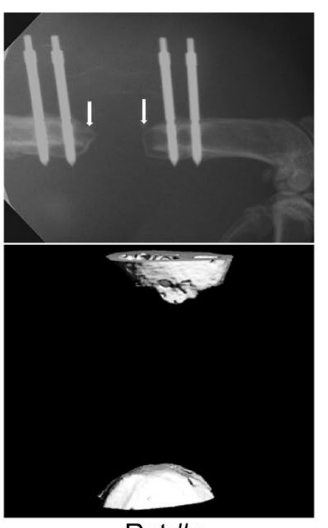

Rat \#c

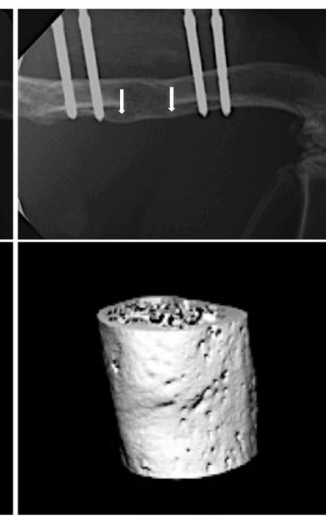

Rat \#f

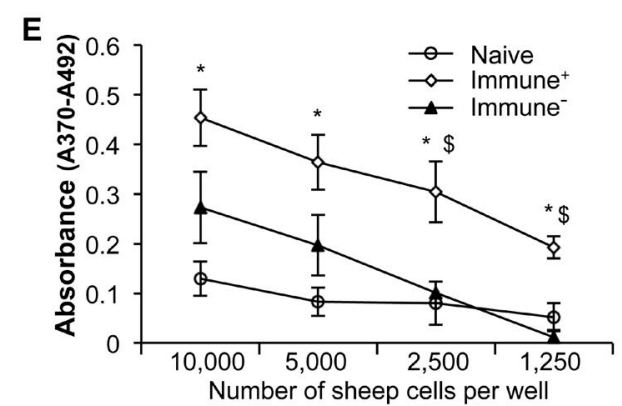

\section{F.}

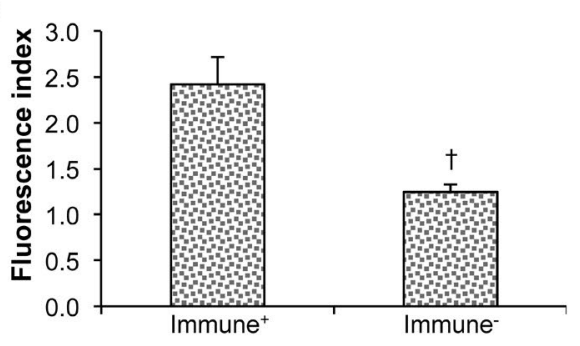

G

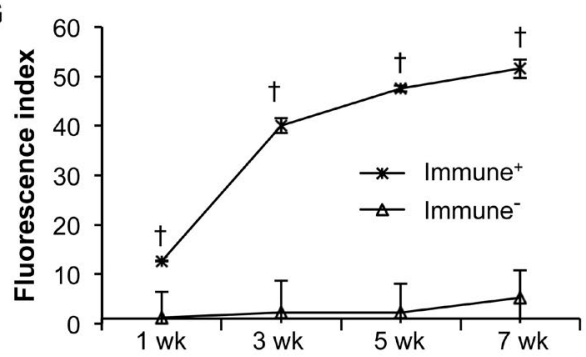

Fig. 2. Bone healing in immunosuppressed Fischer 344 rats. Radiologic findings: Representative X-rays (A, C) and corresponding high resolution $\mu \mathrm{CT}(\mathbf{B}, \mathbf{D})$ scans taken at 8 weeks, showing new bone formation in rats receiving grafts of genetically modified sheep fat $(\mathbf{A}, \mathbf{B})$ or muscle $(\mathbf{C}, \mathbf{D})$. Immunologic findings: (E) Proliferation of splenocytes recovered from rats receiving grafts of genetically modified sheep muscle. Data are presented as mean values $\times 10^{3}$ \pm SEM; * and $\$$ denote a significant difference $(p<0.05)$ relative to naïve control group and immunocompetent group (Immune ${ }^{+}$) group, respectively. (F) Rat anti-sheep IgM responses at $8 \mathrm{~d}$. (G) IgG xenoantibody responses over time following sheep muscle implantation. $\dagger$ indicates a significant difference when compared to control (Immune ${ }^{+}$) group at respective time-points $(p<0.05)$. For the immunosuppressed (Immune') group, no significant difference existed between different time-points. All immunoassays were run in triplicate.

deformation and applied load data were acquired at $10 \mathrm{~Hz}$. The torque and rotation data were used to calculate the torsional stiffness and strength of the healed defect.

\section{Histology}

The defect regions were removed from euthanised rats and fixed in $4 \%$ ice cold paraformaldehyde for $48 \mathrm{~h}$ at $4{ }^{\circ} \mathrm{C}$ before decalcification with $20 \%$ EDTA in $0.1 \mathrm{M}$ phosphate buffer ( $\mathrm{pH}$ 7.4). Extracted femora were maintained in EDTA solution for 4 weeks and tested with a needle as the decalcification proceeded. The specimens were subsequently dehydrated in graded ethanol and embedded in paraffin. Serial $5 \mu \mathrm{m}$ paraffin sections were placed on poly-L-lysine-coated slides, and dried overnight. Sections were stained with either haematoxylin-eosin or safranin orange-fast green, and then examined and photographed under light microscopy.

\section{Statistical analysis}

Comparisons of continuous variables between two treatment groups were performed using a two-tailed Student's $t$-test, and between three groups by analysis of variance (One Way-ANOVA). If the difference between the control and the treatment groups was significant, a post-hoc test (Tukey) was performed. Data are presented as means \pm standard deviation (SD), unless otherwise noted as means \pm standard error of a mean (SEM). The results were taken to be statistically significant at a probability level of $p<0.05$.

\section{Results}

\section{Bone healing in athymic rats}

Athymic rats were used because of their reported ability to accept xenografted tissue. Their use in an orthopaedic context has been published previously (Burastero et al., 2010; Schmitt et al., 2013; Yuan et al., 2013).

Three days after transduction with Ad.BMP-2, discs of sheep muscle each secreted 1.2 $\pm 0.2 \mathrm{ng}$ BMP-2/disc/d. Discs of sheep fat produced $3.3 \pm 0.3 \mathrm{ng} \mathrm{BMP}-2 / \mathrm{disc} / \mathrm{d}$. At this stage, both tissues were implanted into athymic rats. In preliminary screening experiments, 4 genetically modified muscle discs were implanted into $5 \mathrm{~mm}$ segmental defects 


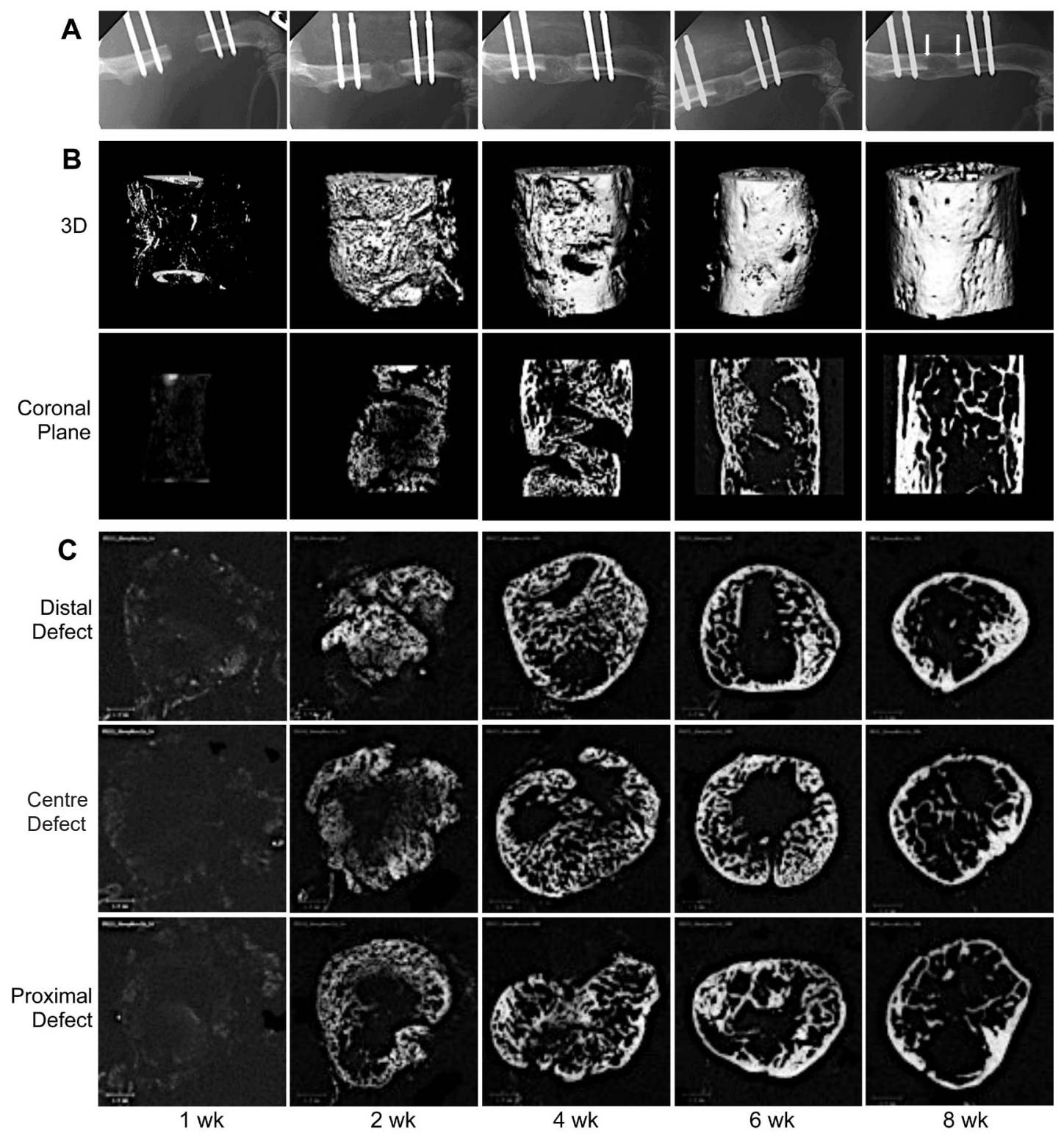

Fig. 3. Serial radiographs and $\mu \mathrm{CT}$ scans of femoral defects treated with genetically modified sheep muscle. Criticalsized segmental femoral defects in Fischer F344 rats were implanted with Ad-BMP2 transduced sheep muscle grafts and transiently immunosuppressed. X-rays (A) were taken weekly and the defects were then harvested for $\mu \mathrm{CT}$ scans (B, 3-dimensional and coronal images; $\mathbf{C}$, cross sectional images) at progressive time-points after surgery. Arrowheads in panel A, 8 weeks indicate the original defect boundaries. Scale bar $=1 \mathrm{~mm}$.

in each of 6 athymic rats, and 4 genetically modified fat discs were implanted into each of 3 athymic rats. Healing was monitored by X-ray and micro-computed tomography $(\mu \mathrm{CT})$. None of the defects receiving genetically modified fat healed. A substantial amount of bone formed in only one of the three defects treated in this way (Fig. 1A, B rat \#1), while the other two defects showed no healing (e.g. Fig. 1A, B rat \#2). With genetically modified muscle discs, one rat did not heal (Fig. 1C, D rat \#3); defects of 3 rats partially healed (e.g. Fig. 1C, D rat \#4); two rats healed rapidly, and by 8 weeks showed complete bridging by $\mathrm{X}$-ray (e.g. Fig. 1C, rat \#5) and $\mu \mathrm{CT}$ (e.g. Fig. 1D, rat \#5).

Further analysis revealed that the variation in healing when using genetically modified muscle was associated with the level of anti-sheep IgG present in the serum (Fig.1E). In particular, high levels of anti-sheep IgG production were associated with impaired healing (e.g. rat \#3; Fig. 1C, D and E), while low or absent ant-sheep IgG production was associated with complete bridging (e.g. rat\#5; Fig. 1C, D and E).

Thus, certain athymic rats mounted immune responses to the xenografted sheep tissue, leading to the hypothesis that immune mechanisms were limiting healing. Because similar data were obtained with athymic rats obtained from 2 different suppliers (data not shown), we decided instead to use wild-type Fischer 344 rats and determine whether immunosuppression would enable the engraftment of sheep tissues and allow bone healing to occur.

Bone healing in immunosuppressed Fischer rats In a preliminary study, 9 rats were immunosuppressed continuously with a combination of FK506 (tacrolimus) 
Fig. 4. BMP-2 content of defects treated with genetically modified sheep muscle. BMP-2 content within extracts of rat femur defects was measured by ELISA and standardised to total protein. * indicates a significant increase $(p<0.05)$ of $3 \mathrm{~d}$ group compared to all other groups; $\$$ indicates a significant increase $(p<0.05)$ of 1 week (wk) group compared to all later time points.

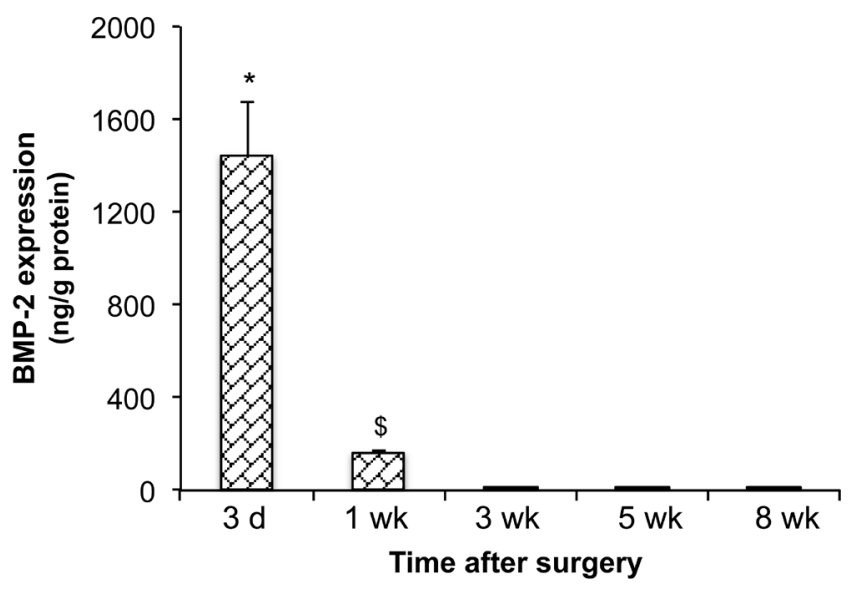

and SEW2871. Three of these rats received genetically modified sheep fat, and 6 received genetically modified sheep muscle.

Immunosuppression improved the formation of bone within defects receiving genetically modified fat, but only one of the 3 defects bridged with new bone (Fig. 2A, B). However, femoral defects of all six rats receiving genetically modified muscle had bridged 8 weeks after receiving the implant; three examples are shown in Fig. $2 \mathrm{C}, \mathrm{D}$. This was associated with suppressed cell-mediated immune responses when splenocytes from these rats were co-cultured with irradiated sheep cells (Fig. 2E). Immunosuppression also reduced the secretion of antisheep IgM into the serum (Fig. 2F) by $8 \mathrm{~d}$, and prevented the progressive production of anti-sheep $\operatorname{IgG}$ over the course of the experiment (Fig. 2G). Both of these responses were strongly inhibited by the immunosuppressive regimen.

In subsequent experiments the period of immunosuppression was reduced to 3 weeks. This was found sufficient to eliminate anti-sheep immune responses for the entire 8 weeks of the experiment (data not shown) and allow healing of the defects.

\section{Time course of healing in transiently immunosuppressed Fischer rats}

Based upon the data shown in Fig. 2, a larger study comprising 24 transiently immunosuppressed and 12 unsuppressed control rats, was undertaken using genetically modified sheep muscle. An additional series of 6 transiently immunosuppressed rats received implants of sheep muscle transduced with adenovirus carrying GFP cDNA (Ad.GFP) (Table 1). All 24 immunosuppressed rats successfully healed their femoral defects in the presence of genetically modified sheep muscle expressing BMP-2; data pertaining to these animals are given below. In none of the unsuppressed rats or rats receiving $\mathrm{GFP}^{+}$muscle were the defects healed (data not shown). Healing of defects in immunosuppressed rats receiving genetically modified sheep muscle was studied in greater detail.

A time-course experiment provided X-ray and $\mu \mathrm{CT}$ evidence that, in 6 out of the 24 animals, mineral began to be deposited in the defect one week after implantation of the genetically modified sheep muscle (Fig. 3). Complete bridging occurred in all animals by 2 weeks. Thereafter, vigorous re-modelling reduced the presence of trabecular bone and led to neo-cortication (Fig. 3).

In an additional series of experiments, protein was extracted from the region of the defect and the BMP-2 content measured by ELISA. As shown in Fig. 4, BMP-2 content was high $3 \mathrm{~d}$ after implantation of the genetically modified muscle. This fell considerably by 1 week, and was undetectable at 3 weeks and beyond.

Histological examination (Fig. 5) confirmed the radiologic data. At 1 week, staining with haematoxylin and eosin (H\&E) showed the presence of the implanted muscle surrounded by an inflammatory cell infiltrate (Fig. $5 \mathrm{~A}, \mathrm{~B})$. At 2 weeks, however, most of the muscle had been replaced by woven bone, with islands of residual cartilage still visible at 3 weeks as confirmed by staining with safranin orange-fast green (Fig. 5C). Lamellar bone began to appear at this point, with neo-cortication and the presence of marrow becoming increasingly prominent. By the time the experiment was terminated at 8 weeks, cortices had been formed, cartilage was no longer visible and an abundant marrow was present, with only a little intramedullary trabecular bone.

At 8 weeks, the quality of the healed defects was assessed by dual-energy X-ray absorptiometry (DXA), quantitative $\mu \mathrm{CT}$ analysis and mechanical testing, using the equivalent position on the contralateral femur for comparison, and defects where rats had not been immunosuppressed as negative controls (Fig. 6). At this time the bone mineral content of the healed defects and the area of bone within the former defect were at near normal values (Fig. 6A, B). The total area within the defect was higher than normal (Fig. 6C), whereas the neo-cortices were thinner than normal (Fig. 6D). Mechanical testing showed that the healed bone was about $15 \%$ stiffer than normal (Fig. 6E), and had recovered approximately $75 \%$ of normal strength (Fig. 6F).

\section{Possible influence of immunosuppressive drugs}

To gain insight into the possible influence on the healing process of the immunosuppressive drugs, we undertook 2 series of experiments. In the first, we compared the properties of the bone formed by transiently immunosuppressed Fischer 344 rats with those of the bone 

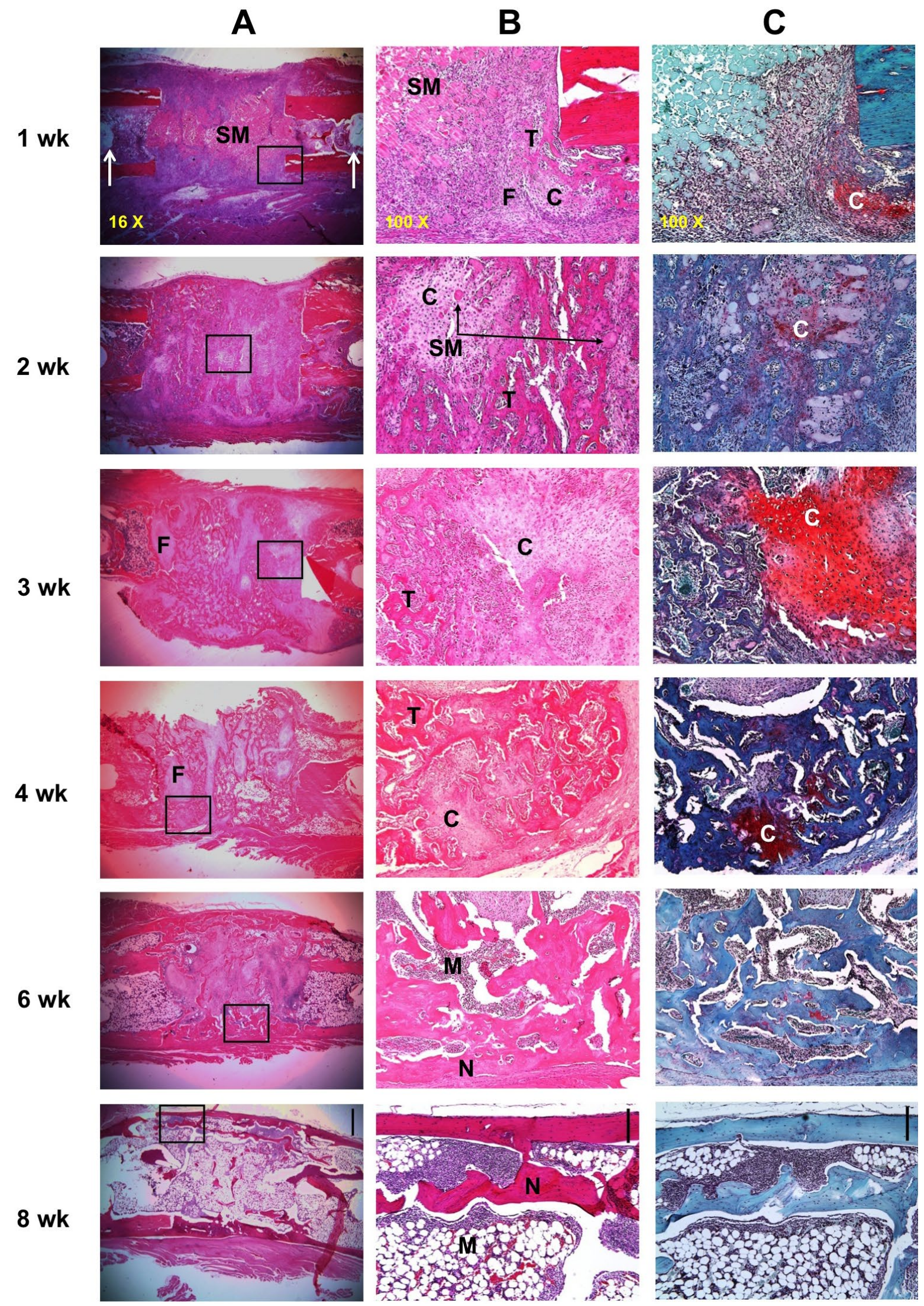

Fig. 5. Histological appearance of defects during healing in transiently immunosuppressed rats. Ad.BMP-2 transduced sheep muscle grafts were implanted into defects in Fischer 344 rats and harvested for histology at different time-points. Rats were immunosuppressed for 3 weeks. (A) Representative images of sections stained with haematoxylin and eosin under low magnification (scale bar in 8 week panel $=1 \mathrm{~mm}$ ). The boxed regions shown in panel A are shown at high magnification (scale bar $=0.2 \mathrm{~mm})(\mathbf{B})$ and stained with safranin orange-fast green (scale bar $=0.2 \mathrm{~mm})(\mathbf{C})$. Arrows in panel $\mathrm{A}, 1$ week, indicate the pin holes of the external fixator. $\mathrm{N}$ indicates new cortical bone, $\mathrm{C}$ indicates cartilage, $\mathrm{T}$ indicates trabecular bone, $\mathrm{M}$ indicates bone marrow, SM indicates sheep muscle tissue, and F indicates fibrous tissue. 
Fig. 6. Physical properties of the defects 8 weeks after implantation of genetically modified, sheep muscle grafts. (A) Bone mineral content, (B) Bone area, (C) Total callus area, (D) Cortical thickness, (E) Stiffness, (F) Strength measured as maximum torque. ${ }^{*}$ denotes significant difference $(p<0.05)$ when compared to intact contralateral femur group; $\dagger$ indicates significant difference $(p<0.05)$ relative to immunocompetent (Immune $^{+}$) group. It was not possible to perform mechanical testing on non-immunosuppressed (Immune-) samples and these had no cortices.
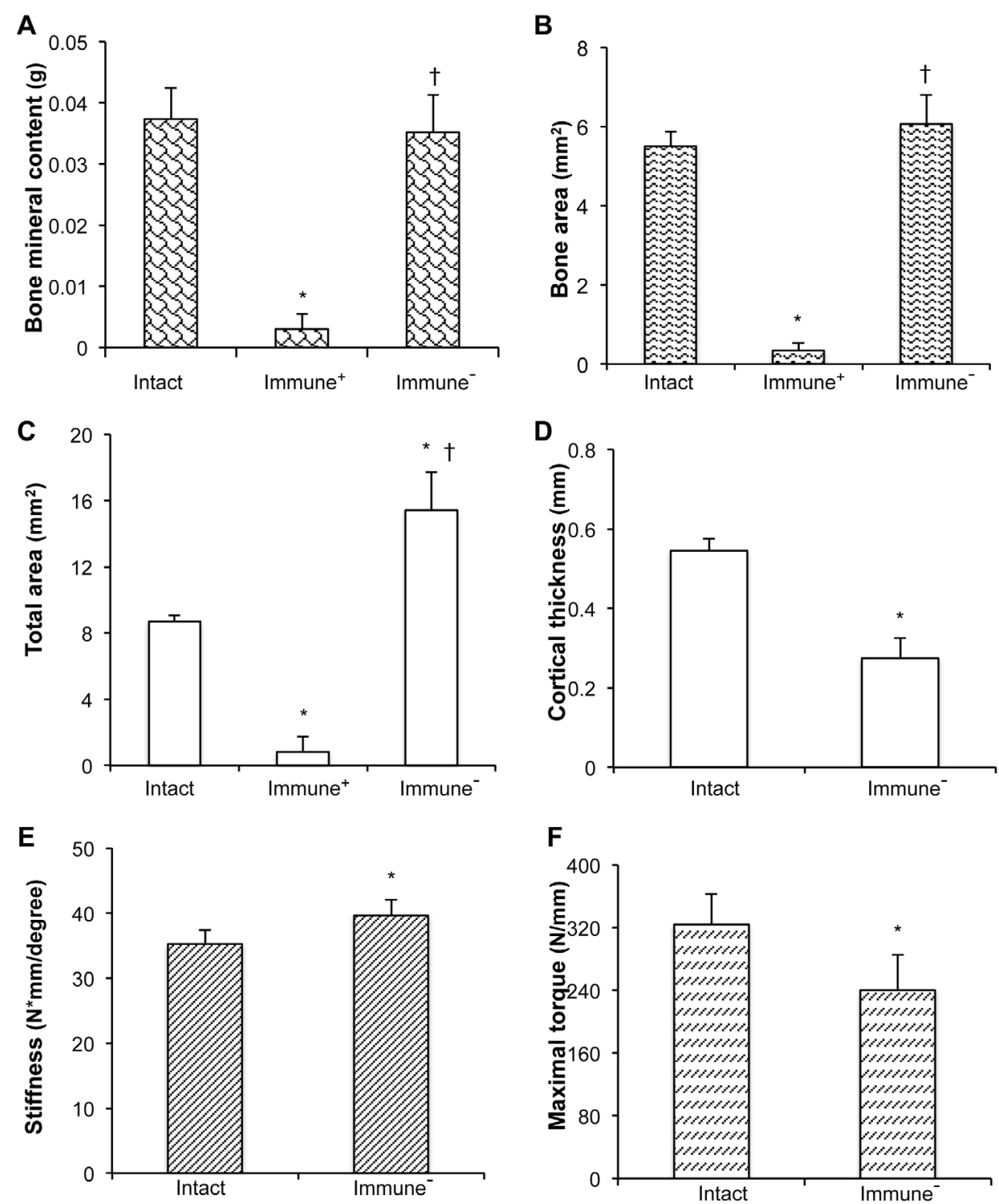

formed by the sub-set of athymic rats that deposited bone after sheep muscle implantation in the absence of drugs. In the second, we assessed the influence of transient immunosuppression on the healing of defects in Fischer 344 rats in response to recombinant, human (rh) BMP-2; these animals did not receive genetically modified muscle.

Data from the first series of experiments (Fig. 7) confirm that, in the reliable absence of a xenograft response, genetically modified sheep muscle efficiently heals critical size defects in the rat femur, regardless of the presence or absence of immunosuppressive drugs. However, there are interesting differences in the appearance of the regenerates. Under $\mu \mathrm{CT}$ analysis, the bone formed in the athymic animals (Fig. 7B) appeared less mature, with far more intramedullary trabecular bone, than that formed under immunosuppression (Fig. 7C). The presence of residual cartilage in the athymic animals at 8 weeks (Fig. 7E), unlike the immunosuppressed animals (Fig. 7F), also suggests slower ossification and maturation.

The mechanical properties, bone density and structure of the contralateral femora were not influenced by the immunosuppressive regimen (data not shown).
Immunosuppression did not have a major effect on the healing of defects in response to rhBMP-2 (Fig. 8), further suggesting that the successful healing of osseous defects in rats by genetically modified sheep muscle could not be explained trivially by the effects of immunosuppression. All defects treated with rhBMP-2 healed.

\section{Discussion}

We have drawn attention to the highly osteogenic properties of muscle and suggested using these as the basis for improving the healing of large osseous defects. Based upon the genetics of the human disease FOP, a sustained BMP signal seems conducive to heterotopic ossification in muscle; in wild-type muscle, transduction with recombinant Ad.BMP-2 provides such a signal.

The present data demonstrate that sheep skeletal muscle, transduced with Ad.BMP-2, can heal critical size defects in vivo very effectively. This suggests that there is no intrinsic reason involving the biology of muscle why there should be a species barrier that forbids the successful 


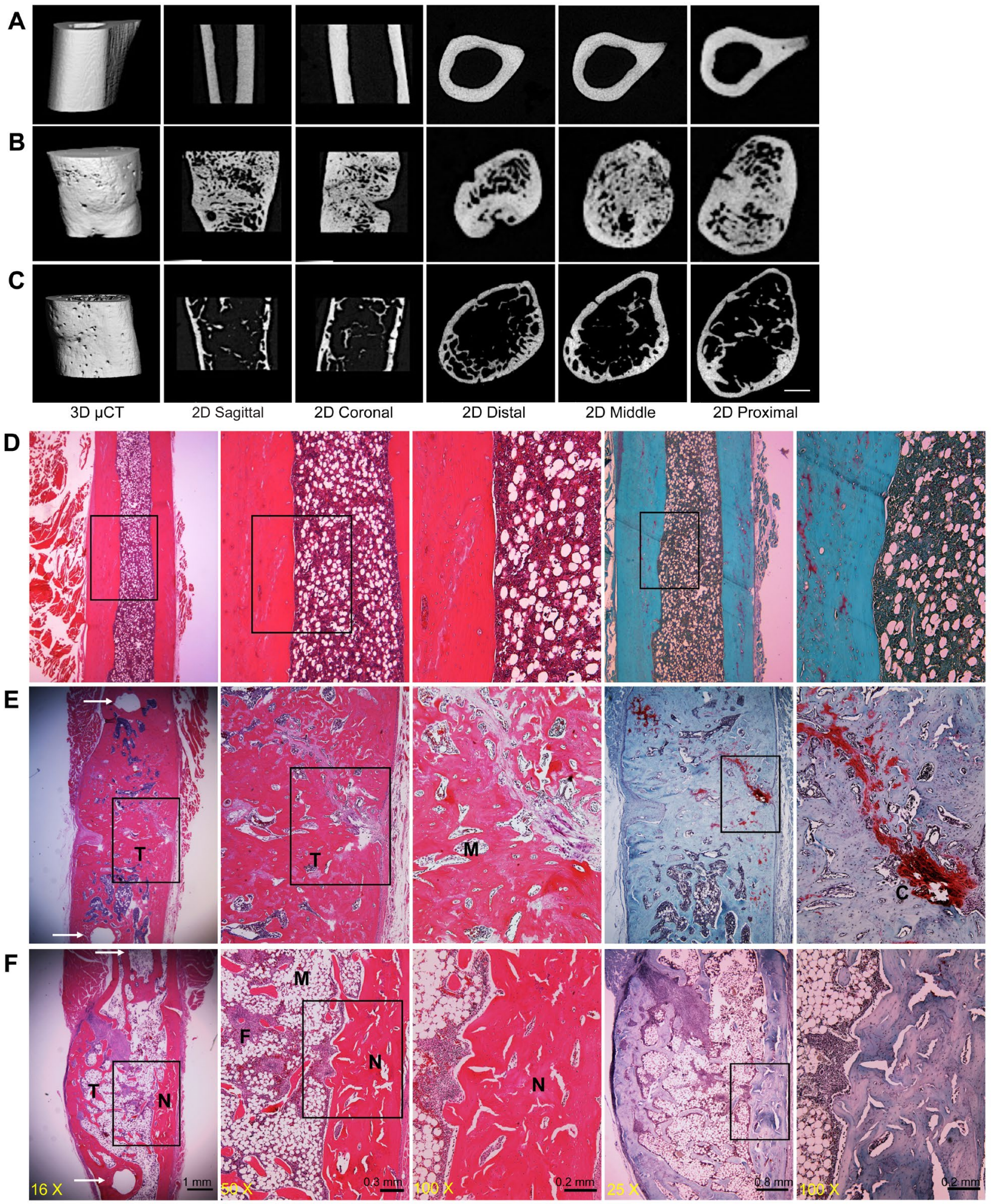

Fig. 7. Comparison of new bone formed in athymic rats and immunosuppressed Fischer 344 rats. Representative $\mu \mathrm{CT}$ images of normal diaphyseal femur (A), and repair bone formed 8 weeks after implantation of genetically modified sheep muscle in athymic rats $(\mathbf{B})$ or in transiently immunosuppressed Fischer 344 rats $(\mathbf{C})$. Representative histological images, shown at progressively higher magnification from left to right, display normal diaphyseal femur (D) and repair bone formed in athymic (E) and immunosupressed (F) rats. Sections were stained with $\mathrm{H} \& \mathrm{E}$ and safranin orange-fast green. Arrows in panels $\mathrm{E}$ and $\mathrm{F}$, left hand panels, indicate the pin holes of external fixator. $\mathrm{N}$ indicates new cortical bone within the defects, $\mathrm{M}$ indicates bone marrow, $\mathrm{T}$ indicates trabecular bone, and $\mathrm{F}$ indicates fibrous tissue. 

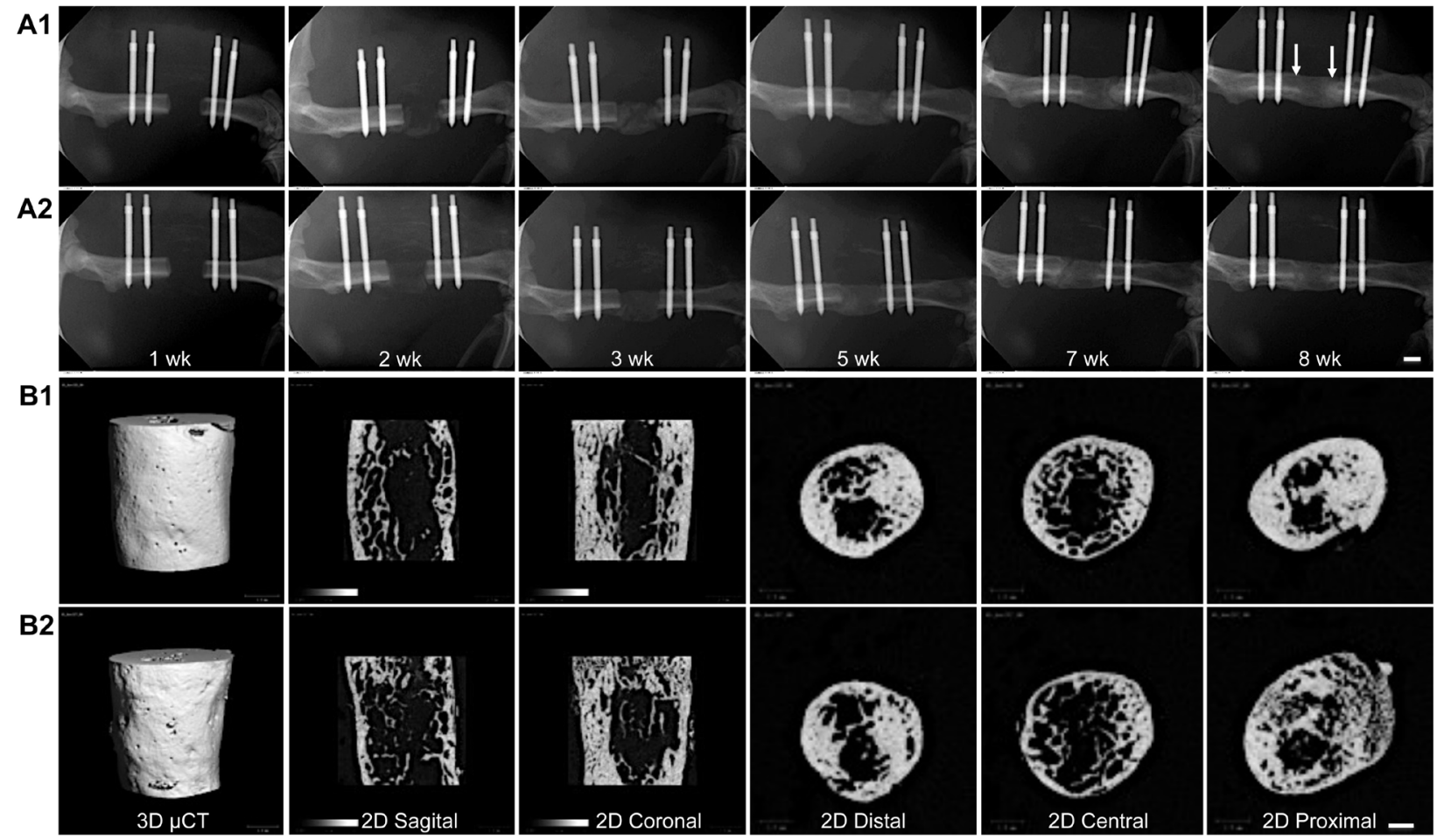

C
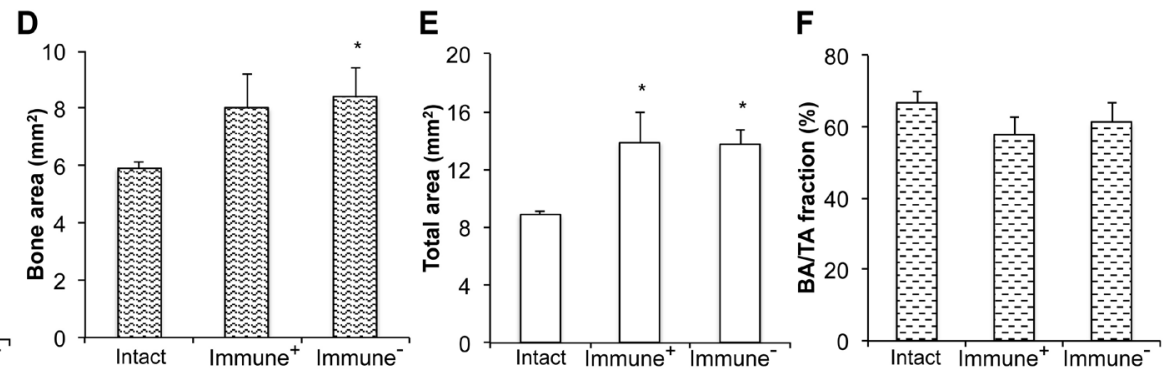

Fig. 8. Effects of transient immunosuppression on bone healing in response to rhBMP-2. Radiology: Serial X-ray images $(\mathbf{A 1}, \mathbf{A 2})$ and $\mu \mathrm{CT}$ images at 8 weeks $(\mathbf{B 1}, \mathbf{B 2})$ of defects during healing in the absence $(\mathbf{A} 1, \mathbf{B} 1)$ or presence (A2, B2) of immunosuppression. Arrows in panel A1, 8 weeks, indicate the original defect boundaries. Scale bars $=1 \mathrm{~mm}$. Physical properties: Bone mineral content $(\mathbf{C})$, Bone area $(\mathbf{D})$, Total callus area $(\mathbf{E})$, and Bone area/ Total area or Callus size (F, BA/TA, \%).

translation of this technology to sheep, as a prelude to human trials. It is remarkable that such rapid and efficient healing was observed when the genetically modified sheep muscle discs were collectively making a total of only $\sim 5 \mathrm{ng}$ BMP-2/d at the time of implantation. By one week, the amount of BMP-2 in the defect had dropped by $\sim 80 \%$ and BMP-2 became undetectable by 3 weeks. This means that the total dose of BMP-2 delivered to the defect is probably in the nanogram range. If delivered as a recombinant protein, this amount of BMP-2 has no effect in this model; in our hands, $11 \mu \mathrm{g}$ rhBMP-2 is normally needed to obtain robust, reliable healing (Betz et al., 2006; Betz et al., 2007; Glatt et al., 2009; Glatt et al., 2012).

The time-course of healing is also noteworthy. Considerable amounts of bone had formed by 2 weeks, by which time the amount of BMP-2 within the defect had fallen by over $80 \%$. At 3 weeks, BMP-2 was no longer measurable. When the immunosuppressive drugs were withdrawn at this time, anti-sheep immune reactions did not develop and it was no longer necessary to immunosuppress to achieve reliable bone healing. Sheep muscle could no longer be seen histologically in the defect at 3 weeks, all of which suggests that the sheep cells were no longer present after 3 weeks, having been turned over during the rapid remodelling that occurs. The conclusion that events occurring early after implantation are critical to the success of healing agrees with recent data concerning the importance of mechanical and biological influences occurring in this period (Glatt et al., 2012; Schmidt-Bleek et al., 2014). These data are interesting in light of the observations of Sonnet et al. (2013) who, in a similar rat segmental defect model, obtained rapid healing with very low doses of BMP-2 delivered by encapsulated, genetically modified, allogeneic cells.

Athymic rats are frequently used in studies of regenerative orthopaedics, and we were surprised to find a xenograft response to sheep cells. The ex vivo method used in this study eliminates immune responses to the adenovirus that was used (Evans et al., 2009). The presence of anti-sheep immune responses agrees with data from the 
transplant literature indicative of xenograft responses in athymic rats (Xia et al., 2000), which are outbred. Using immunosuppressed wild-type rats as an alternative brings advantages of cost, availability and uniformity of the animals.

Application of FK506 and SEW2871 raises the question of whether these immunosuppressive drugs enhance bone healing, as suggested by some studies (Voggenreiter et al., 2000; Tang et al., 2002), thereby providing misleading results. However, bone did form in a sub-set of athymic rats, suggesting that the xenografted muscle did not require such drugs to form bone in these particular animals. Moreover, the immunosuppressive drugs had no major effects on healing of defects in Fischer 344 rats in response to rhBMP-2. This agrees with earlier observations that FK506 has no effect on fracture healing in rats (Voggenreiter et al., 2005). The observation that genetically modified fat failed to provoke a robust osteogenic response in the immunosuppressed rats, despite expressing comparable amounts of BMP-2 to muscle, further suggests that the absence of an immune response is not responsible for the high effectiveness of muscle.

Although fat is a more convenient source of donor tissue than muscle, its osteogenic properties in vivo were less reliable. The constituents of muscle that contribute to its higher osteogenic potential are unknown, but include osteoprogenitor cells, secreted osteogenic factors and components of the extracellular matrix. In preliminary experiments, we failed to trigger an osteogenic response in vivo by implanting decellularised muscle (data not shown). However, muscle is known to be a rich source of progenitor cells, including satellite cells, mesenchymal stem cells and muscle-derived stem cells (Judson et al., 2013), as well as endothelial cells from its blood vessels (Lounev et al., 2009). The use of Ad.GFP to label transduced cells within muscle may help identify contributing cell types. Muscle also secretes multiple myokines (Pedersen, 2013), many of which could contribute to osteogenesis in conjunction with transgenic BMP-2. More research is required to elucidate these matters.

\section{Acknowledgments}

The authors thank Prof. Angus Thompson of the University of Pittsburgh School of Medicine for advice concerning immunosuppression with FK506 and SEW2871. This work was funded by NIAMS grant number RO1 AR050243 and the AO Foundation (GENDEF). We wish to confirm that there are no known conflicts of interest associated with this publication and there has been no significant financial support for this work that could have influenced its outcome.

\section{References}

Baltzer AW, Lattermann C, Whalen JD, Braunstein S, Robbins PD, Evans CH (1999) A gene therapy approach to accelerating bone healing. Evaluation of gene expression in a New Zealand white rabbit model. Knee Surg Sports Traumatol Arthrosc 7: 197-202.
Balzer AW, Lattermann C, Whalen JD, Ghivizzani S, Wooley P, Krauspe R, Robbins PD, Evans CH (2000) Potential role of direct adenoviral gene transfer in enhancing fracture repair. Clin Orthop Rel Res 379S: 120125.

Betz OB, Betz VM, Nazarian A, Pilapil CG, Vrahas MS, Bouxsein ML, Gerstenfeld LC, Einhorn TA, Evans $\mathrm{CH}$ (2006) Direct percutaneous gene delivery to enhance healing of segmental bone defects. J Bone Joint Surg Am 88: $355-365$.

Betz VM, Betz OB, Glatt V, Gerstenfeld LC, Einhorn TA, Bouxsein ML, Vrahas MS, Evans CH (2007). Healing of segmental bone defects by direct percutaneous gene delivery: effect of vector dose. Hum Gene Ther 18: 907915.

Burastero G, Scarfi S, Ferraris C, Fresia C, Sessarego N, Fruscione F, Monetti F, Scarfo F, Schupbach P, Podesta M, Grappiolo G, Zocchi E (2010) The association of human mesenchymal stem cells with BMP-7 improves bone regeneration of critical-size segmental bone defects in athymic rats. Bone 47: 117-126.

Crystal RG (2014) Adenovirus: the first effective in vivo gene delivery vector. Hum Gene Ther 25: 3-11.

DeCoster TA, Gehlert RJ, Mikola EA, Pirela-Cruz MA (2004) Management of posttraumatic segmental bone defects. J Am Acad Orthop Surg 12: 28-38.

Diefenderfer DL, Osyczka AM, Garino JP, Leboy PS (2003) Regulation of BMP-induced transcription in cultured human bone marrow stromal cells. J Bone Joint Surg Am 85 Suppl 3: 19-28.

Dumic-Cule I, Pecina M, Jelic M, Jankolija M, Popek I, Grgurevic L, Vukicevic S (2015) Biological aspects of segemental bone defects management. Int Orthop 39: 1005-1011.

Egermann M., Baltzer AW, Adamaszek S, Evans C, Robbins P, Schneider E, Lill CA (2006a) Direct adenoviral transfer of bone morphogenetic protein-2 cDNA enhances fracture healing in osteoporotic sheep. Hum Gene Ther 17: 507-517.

Egermann M, Lill CA, Griesbeck K, Evans CH, Robbins PD, Schneider E, Baltzer AW (2006b) Effect of BMP-2 gene transfer on bone healing in sheep. Gene Ther 13: $1290-1299$.

Evans CH (2010) Gene therapy for bone healing. Expert Rev Mol Med 12: e18.

Evans C (2011a) Gene therapy for the regeneration of bone. Injury 42: 599-604.

Evans CH (2011b) Barriers to the clinical translation of orthopedic tissue engineering. Tissue Eng Part B Rev 17: 437-441.

Evans CH (2013) Advances in regenerative orthopedics. Mayo Clin Proc 88: 1323-1339.

Evans CH, Robbins PD (1999) Genetically augmented tissue engineering of the musculoskeletal system. Clin Orthop Relat Res 367: S410-418.

Evans CH, Ghivizzani SC, Robbins PD (2004) Orthopaedic gene therapy. Clin Orthop Relat Res 429: 316-329.

Evans CH, Palmer GD, Pascher A, Porter R, Kwong FN, Gouze E, Gouze JN, Liu F, Steinert A, Betz O, Betz V, Vrahas M, Ghivizzani SC (2007) Facilitated endogenous 
repair: making tissue engineering simple, practical, and economical. Tissue Eng 13: 1987-1993.

Evans CH, Liu FJ, Glatt V, Hoyland JA, Kirker-Head C, Walsh A, Betz O, Wells JW, Betz V, R. M. Porter RM, Saad FA, Gerstenfeld LC, Einhorn TA, Harris MB, Vrahas MS (2009) Use of genetically modified muscle and fat grafts to repair defects in bone and cartilage. Eur Cell Mater 18: 96-111.

Glatt V, Kwong FN, Park K, Parry N, Griffin D, Vrahas M, Evans CH, Harris M (2009) Ability of recombinant human bone morphogenetic protein 2 to enhance bone healing in the presence of tobramycin: evaluation in a rat segmental defect model. J Orthop Trauma 23: 693-701.

Glatt V, Miller M, Ivkovic A, Liu F, Parry N, Griffin D, Vrahas M, Evans C (2012) Improved healing of large segmental defects in the rat femur by reverse dynamization in the presence of bone morphogenetic protein-2. J Bone Joint Surg Am 94: 2063-2073.

Gouze JN, Stoddart MJ, Gouze E, Palmer GD, Ghivizzani SC, Grodzinsky AJ, Evans CH (2004) In vitro gene transfer to chondrocytes and synovial fibroblasts by adenoviral vectors. Methods Mol Med 100: 147-164.

Judson RN, Zhang RH, Rossi FM (2013) Tissueresident mesenchymal stem/progenitor cells in skeletal muscle: collaborators or saboteurs? FEBS J 280: 41004008

Lounev VY, Ramachandran R, Wosczyna MN, Yamamoto M, Maidment AD, Shore EM, Glaser DL, Goldhamer DJ, Kaplan FS (2009) Identification of progenitor cells that contribute to heterotopic skeletogenesis. J Bone Joint Surg Am 91: 652-663.

Mi Z, Ghivizzani SC, Lechman E, Glorioso JC, Evans CH, Robbins PD (2003) Adverse effects of adenovirusmediated gene transfer of human transforming growth factorbeta 1 into rabbits knees. Arthritis Res Ther 5: R132-R139.

Muschler GF, Raut VP, Patterson TE, Wenke JC, Hollinger JO (2010) The design and use of animal models for translational research in bone tissue engineering and regenerative medicine. Tissue Eng Part B Rev 16: 123-145.

Nauth A, Giles E, Potter BK, Nesti LJ, O’Brien P, Bosse MJ, Anglen JO, Mehta S, Ahn J, Miclau T, Schemitsch EH (2012) Heterotopic ossification in orthopaedic trauma. J Orthop Trauma 26: 684-688.

Niyibizi C, Baltzer A, Lattermann C, Oyama M, Whalen JD, Robbins PD, Evans CH (1998) Potential role for gene therapy in the enhancement of fracture healing. Clin Orthop Relat Res 355: S148-153.

Pedersen BK (2013) Muscle as a secretory organ. Compr Physiol 3: 1337-1362.

Pensak MJ, Lieberman JR (2013) Gene therapy for bone regeneration. Curr Pharm Des 19: 3466-3473.

Schmidt-Bleek K, Petersen A, Dienelt A, Schwarz C, Duda GN (2014) Initiation and early control of tissue regeneration - bone healing as a model system for tissue regeneration. Expert Opin Biol Ther 14: 247-259.

Schmitt T, Fox PM, Woon CY, Farnebo SJ, Bronstein JA, Behn A, Pham H, Chang J (2013) Human flexor tendon tissue engineering: in vivo effects of stem cell reseeding. Plast Reconstr Surg 132: 567e-576e.
Seok J, Warren HS, Cuenca AG, Mindrinos MN, Baker HV, Xu W, Richards DR, McDonald-Smith GP, Gao H, Hennessy L, Finnerty CC, Lopez CM, Honari S, Moore EE, Minei JP, Cuschieri J, Bankey PE, Johnson JL, Sperry J, Nathens AB, Billiar TR, West MA, Jeschke MG, Klein MB, Gamelli RL, Gibran NS, Brownstein BH, MillerGraziano C, Calvano SE, Mason PH, Cobb JP, Rahme LG, Lowry SF, Maier RV, Moldawer LL, Herndon DN, Davis RW, Xiao W, Tompkins RG (2013) Genomic responses in mouse models poorly mimic human inflammatory diseases. Proc Natl Acad Sci USA 110: 3507-3512.

Shore EM, Xu M, Feldman GJ, Fenstermacher DA, Cho TJ, Choi IH, Connor JM, Delai P, Glaser DL, LeMerrer M, Morhart R, Rogers JG, Smith R, Triffitt JT, Urtizberea JA, Zasloff M, Brown MA, Kaplan FS (2006) A recurrent mutation in the BMP type I receptor ACVR1 causes inherited and sporadic fibrodysplasia ossificans progressiva. Nat Genet 38: 525-527.

Sonnet C, Simpson CL, Olabisi RM, Sullivan K, Lazard Z, Gugala Z, Peroni JF, Weh JM, Davis AR, West JL, Olmsted-Davis EA (2013) Rapid healing of femoral defects in rats with low dose sustained BMP2 expression from PEGDA hydrogel microspheres. J Orthop Res 31: 1597-1604.

Tang L, Ebara S, Kawasaki S, Wakabayashi S, Nikaido ST, Takaoka K (2002) FK506 enhanced osteoblastic differentiation in mesenchymal cells. Cell Biol Int 26: 75-84.

Voggenreiter G, Assenmacher S, Kreuzfelder E, Wolf M, Kim MR, Nast-Kolb D, Schade FU (2000) Immunosuppression with FK506 increases bone induction in demineralized isogeneic and xenogeneic bone matrix in the rat. J Bone Miner Res 15: 1825-1834.

Voggenreiter G, Siozos P, Hunkemoller E, Heute S, Schwarz M, Obertacke U (2005) Immunosuppression with FK506 has no influence on fracture healing in the rat. Bone 37: 227-233.

Xia G, Ji P, Rutgeerts O, Waer M (2000) Natural killer cell- and macrophage-mediated discordant guinea pig $\rightarrow$ rat xenograft rejection in the absence of complement, xenoantibody and T cell immunity. Transplantation 70: 86-93.

Yuan W, James AW, Asatrian G, Shen J, Zara JN, Tian HJ, Siu RK, Zhang X, Wang JC, Dong J (2013) NELL-1 based demineralized bone graft promotes rat spine fusion as compared to commercially available BMP-2 product. J Orthop Sci 18: 646-657.

\section{Discussion with Reviewers}

Reviewer I: At least two major story lines appear to be present in this paper (starting in the introduction): the role of immunosuppression on regeneration, the role of genetically modified muscle and fat tissue on bone defect healing, the comparison of bone and fat as origin of BMP transfected stimulation. Which story is the main story and how would you rank the others accordingly?

Authors: The flow of the discussion reflects the rank order of the "stories". Thus, after an opening paragraph, there 
is a paragraph with the lead story that: "The present data demonstrate that sheep skeletal muscle, transduced with Ad.BMP-2, can heal critical sized defects in vivo very effectively." The following paragraph deals with what we consider to be the second most important finding, namely that the bone healing began rapidly and occurred under conditions of low and fairly transient BMP-2 expression. The final paragraph starts "Application of FK506 and SEW2871 raises the question of whether immunosuppressive drugs enhance bone healing, ...", which we consider to be the next most interesting issue raised by our studies. At the end of this paragraph, we note that muscle is more effective than fat and discuss the components of muscle that could contribute to its high osteogenicity.

Reviewer II: What muscle-specific factors are likely to be responsible for enhanced fracture healing in combination with the expressed BMP-2? In addition to the presence of stem cells, and other trophic factors, does the muscle ECM also play a role, e.g. by facilitating attachment and recruitment of endogenous osteoblasts/osteoclasts.

Authors: We conducted a preliminary experiment where decellularised muscle was implanted, but this failed to initiate osteogenesis. Thus, myokines or progenitor cells derived from muscle are more likely than extracellular matrix to play key roles in osteogenesis. The secretome of muscle is quite complex, and a number of different types of progenitor cells exist in muscle, so this will take some sorting out.
Reviewer II: How much is healing likely to be influenced by the anatomical site of skeletal tissue harvest?

Authors: This is an interesting question. Because progenitor cells may be associated with blood vessels within muscle it is possible that, other things being equal, the more highly vascularised muscles are more osteogenic. Moreover, the vascularity of muscle increases with exercise. So there is every possibility that healing will be influenced by the anatomical site of muscle harvest, as well as the physiological status of the donor tissue.

Reviewer II: The repair response at 8 weeks was slightly inferior to intact bone with regard to cortical thickness and maximum torque. Does this represent the maximum repair response, or would further improved healing be anticipated at longer time points? If the response has reached a plateau, what modifications to the experimental approach could be adopted to improve healing even further?

Authors: Because the fixator remains in place during the whole experiment, it will continue to bear load and thus create stress shielding as healing progresses. It would be interesting to remove the fixator once osseous bridging has occurred to allow load bearing. This should enhance maturation and remodelling, thereby enhancing the quality of the healed bone.

Editor's Note: Scientific Editor in charge of the paper: Martin Stoddart. 